\title{
Development of a simple selection protocol for optimizing the harvest of mesenchymal stem cells from explanted human umbilical cord Wharton's jelly
}

\author{
Takhelmayum Paras Singh", Mingma Lhamu Sherpa ${ }^{2}$, Anup Pradhan ${ }^{3}$, \\ Takhelmayum Amumacha Singh ${ }^{4}$
}

${ }^{1}$ Lecturer, ${ }^{2}$ Professor, ${ }^{4}$ Professor and Head, Department of Biochemistry, Sikkim Manipal Institute of Medical Sciences, Sikkim Manipal University, Gangtok, Sikkim, ${ }^{3}$ Professor and Head, Department of Obstetrics and Gynaecology, Sikkim Manipal Institute of Medical Sciences, Sikkim Manipal University, Gangtok, Sikkim, India

\section{A B S T R A C T}

Background: Human umbilical cord Wharton's jelly (hUCWJ) derived Mesenchymal stem cells (MSCs) is a non-controversial, easily available source of human tissue which has a close association with embryonic tissue. Explant culture technique of isolating MSCs do not require any proteolytic enzymes giving an edge when compared to enzymatic methods. Aims and Objective: This study was designed to develop a suitable protocol to optimize the number of primary cells by transferring the explants after a successful migration and before trypsinizing of MSCs from primary culture plate to new culture plates. Materials and Methods: For defining the isolated cells as MSCs, the cells were studied by colony forming assay, semiquantitative two steps reverse transcriptase polymerase chain reaction (RT-PCR) and International Society for Cellular Therapy (ISCT) criteria to determine the purity of the lineage. Results: The explant cultured cells fulfil the defining criteria by ISCT. Further, they form colony and RT-PCR confirmed the presence of thy-1, endoglin and $\beta$-actin. The incubated explant shows successful cells migration after transferring from one culture plate to another for five consecutive times. Further, it was seen that the migrated cells can be cultured for more than 18 passages. However, a reduction was seen in the migration of the cells after the $3^{\text {rd }}$ transfer of the explants. Conclusion: This study found that the transferred explant has the potential to yield cells for 5 consecutive explant transfers. Further, this technique optimized the yield of primary cells and thereby reducing the quantity and frequency of sample collection, processing time and cost.

Keywords: Explant; Mesenchymal stem cells; Mesenchymal stromal cells; Neonatal; Primitive nature; Wharton's jelly

\section{INTRODUCTION}

Mesenchymal stem cells (MSCs) also known as mesenchymal stromal cells are the most widely studied stem cells for therapeutic and research purpose. The MSCs, first isolated by Friendenstein et al in bone marrow, ${ }^{1}$ after that different researchers isolated MSCs from different adult tissues like adipose tissue, ${ }^{2}$ hair follicles, ${ }^{3}$ cornea, ${ }^{4}$ dental pulp, ${ }^{5}$ etc., but as the research advanced MSCs were isolated from different neonatal sources that were more promising and considered superior over adult sources of MSCs due to its close association with extra-embryonic tissue. While comparing MSCs derived from adults versus neonates, a different study has stated that there are decrease proliferation rate, low potential chondrogenic and osteogenic differentiation and increased senescent feature. ${ }^{6}$ Therefore with higher proliferation and expansion potential, the neonates derived MSCs like Wharton's Jelly, ${ }^{7}$ placenta, ${ }^{8}$ Umbilical cord ${ }^{9}$ are 
considered primitive when compared with MSCs obtained from adult tissue like adipose tissue and bone marrow. ${ }^{10}$

Mesenchymal stem cells derived from neonatal tissues like Wharton's jelly can be isolated and used with a minimal ethical issue as the tissue are normally discarded after birth. During evolution, extra embryonic tissue-derived MSCs have been seen to have a close relationship with the embryonic stem cells allowing them to proliferate faster than adult MSCs with extensive multipotent plasticity and importantly immune privileged characteristics. ${ }^{11,12}$ When compared to bone marrow or adipose-derived MSCs, Wharton's jelly MSCs allogenically suppress T cells to a larger extent. Wharton's jelly MSCs express MHC class I (HLA-ABC) at low levels but not class II (HLA-DR) and co-stimulatory antigens such as CD80, CD86 implicated in activation of both $\mathrm{T}$ and $\mathrm{B}$ cells responses. Therefore, they can avoid immune response very similar to other types of native MSCs. ${ }^{13}$ The expression of a distinct strain of cytoskeletal markers, such as Vimentin and Smooth muscle actin (SMA) confirmed the mesenchymal characteristics of Wharton's jelly. ${ }^{14}$

There are two conjectures made, first by Kim et al about the migration of MSCs in Wharton's Jelly stating two floods of movement of fetal MSCs that got caught and lived in the Wharton's jelly matrix of the umbilical cord. Second, the primitive nature of MSCs from Wharton's jelly fibroblast may actually be starting from mesenchyme that is in the umbilical cord matrix at that point as hypothesized by Wang et al. ${ }^{9,15}$

There are two standard methods for obtaining MSCs from expelled gestational tissue namely enzymatic or explant methods. In enzymatic methods, one or more proteolytic enzymes are used and the explant method does not require enzymes and therefore is both time and cost efficient and both methods yield sustainable cells. ${ }^{16}$ Explant culture is a practice where the original tissue is mechanically minced in vitro and placed in culture plates or flask. The cells start to migrate out of the tissue and adhere to the surface of the culture plate without any digestive enzyme. While comparing isolation of MSCs by enzymatic and explant methods Yoon et al. reported that explant methods yield a higher number of MSCs with better viability with an increase of 2-8 times greater number of cells than enzymatic digestion at P0. It has also been reported that a fragment basic fibroblast growth factors (bFGF) is secreted during the primary phase of explant culture due to the transfer of the explant from in vivo to in vitro. ${ }^{17,18}$ The mincing process allows the release of intracellular compounds and cytokines that would promote the migration and establishment of MSCs growth in vitro. Also, the cells are in close association with each other in explant and can tolerate isolation stress better when compare to enzymatic as it goes through the dual step of stress, one while separating from the source and seconds while enzymatic treatment. ${ }^{19}$

There is a growing utilization of gestational tissue for MSCs isolation that can have clinical applications. Before MSCs can be used for therapeutic, one needs an early passage cell and the optimal number of cells for administration. To obtain this early passage and optimal number, a legitimate separation technique needs to be initiated. The cells population concept of MSCs is 1:1000000. Therefore, it is not mandatory that the plated explant will migrate cells and if it migrates; then there is a limited number of MSCs available for further study. Thus, it becomes very important to select those explants which give proper migration of primary cells. This study was conducted to develop a suitable protocol to isolate MSCs from human umbilical cord Wharton's jelly by explant technique without using any growth factors. In this study, the primary explant was transferred from one culture plate to another to optimize migration of MSCs from one culture plate to another for continuous production of primary cells from the primary explant. This modification of the explant technique is being done for the first time with the goal of providing isolation and expanding method which is simple, cost-effective and maximizes the yield of primary cells at P0 from hUCWJ and may further be used for the therapeutic application.

\section{MATERIALS AND METHODS}

This experimental study was conducted for a period of 24 months (16.07.2015 to 15.07.2017) in the Departments of Biochemistry and Obstetrics and Gynaecology, Sikkim Manipal Institute of Medical Sciences \& Central Referral Hospital, SMU, Gangtok after the due approval of the Institutional Review Board. A total number of 22 human umbilical cord tissue samples were collected from the placental ends after the delivery of the baby. Informed consents were obtained from all participating mothers prior to delivery.

The samples were collected, and the explant technique was used to propagate MSCs by incubation and reincubation of the primary explant. MSCs characteristics were defined not only by cell morphology of migrated cells, immunophenotyping, adipogenic differentiation, chondrogenic differentiation, in vitro trilineage differentiation but also defined by colony forming unit (CFU), ribose nucleic acid (RNA) isolation and reverse transcriptase polymerase chain reaction (RT-PCR) in the following manner.

Collection of UCWJ: Around $10 \mathrm{~cm}$ long hUCWJ was collected from the placental end in $50 \mathrm{ml}$ tube containing 
$32 \mathrm{ml}$ of Hank's Balanced Salt Solution (Gibco, USA) supplemented with $300 \mathrm{U} / \mathrm{ml}$ penicillin, $300 \mu \mathrm{g} / \mathrm{ml}$ streptomycin, $150 \mu \mathrm{g} / \mathrm{ml}$ gentamicin and $1 \mu \mathrm{g} / \mathrm{ml}$ fungizone (Gibco, USA) under aseptic condition.

\section{Defining MSCs as per criteria. ${ }^{20}$}

Isolation of UCWJ MSCs: Under laminar flow hood cabinet (ESCO, Singapore), the umbilical cord was transferred and washed 3-4 times to remove any blood and blood clots by phosphate buffered saline (PBS) (Sigma, USA) (Figure 1a). The umbilical cord was dissected vertically and the vein and arteries were removed. The remaining part of the cord was diced to make $2-3 \mathrm{~mm}^{2} /$ pieces (Figure $1 \mathrm{~b}$ ). Around 8 diced pieces were transferred to a $35 \mathrm{~mm}$ culture plate $(B D$ Falcon, USA) and allowed to stand for 10 minutes. $2 \mathrm{ml}$ Dulbecco's Modified Eagle Medium low glucose (DMEMLG), Glutamax (Gibco, USA), supplemented with 20\% Fetal bovine serum (FBS) (Gibco, USA) and antibiotics were then added. The culture plate was incubated in a $\mathrm{CO}_{2}$ incubator (New Brunswick, Eppendorf, USA) at $37^{\circ} \mathrm{C}$ and $5 \% \mathrm{CO}_{2}$ for 4 days and the medium was changed every 3 days with $3 \mathrm{ml}$ DMEM supplemented $10 \%$ FBS and antibiotics.

Reincubation of explant for primary culture: Isolation of primary cells comes a long way but mechanical disaggregation, enzymatic disaggregation and primary explant culture remain the main technique. Therefore, for advancing the technique of explant, once the cells migrate, the explant was transferred with the help of a sterile needle to a new culture plate before trypsinization (Figure 1e \& $1 \mathrm{~g})$. This was allowed to stand for 10 minutes and complete medium was added and re-incubated in a $\mathrm{CO}_{2}$ incubator at $37^{\circ} \mathrm{C}$ and $5 \% \mathrm{CO}_{2}$ for 4 days and the medium was changed every 3 days with $3 \mathrm{ml}$ DMEM supplemented, $10 \%$ FBS and antibiotics. This process was repeated for five consecutive times.

Immunophenotyping by Flow Cytometry: International Society for Cellular Therapy (ISCT) has described a panel of markers which need to be expressed by the adherent cell population to label them as MSCs. BD Stemflow Human MSC Analysis Kit (Becton, Dickinson, USA) were used where the antibodies CD73-APC, CD105-PerCP-Cy5.5, CD90-FITC and CD44-PE were used as positive markers and the PE channel open to use in combination with the negative MSC cocktail (PE CD45, PE CD34, PE CD11b, PE CD19 and PE HLA-DR). It also included antibody conjugate for immunophenotyping the MSCs.

In vitro trilineage differentiation: The MSCs have to exhibit trilineage differentiation to adipogenic, chondrogenic and osteogenic lineage. The MSCs was tested as below for
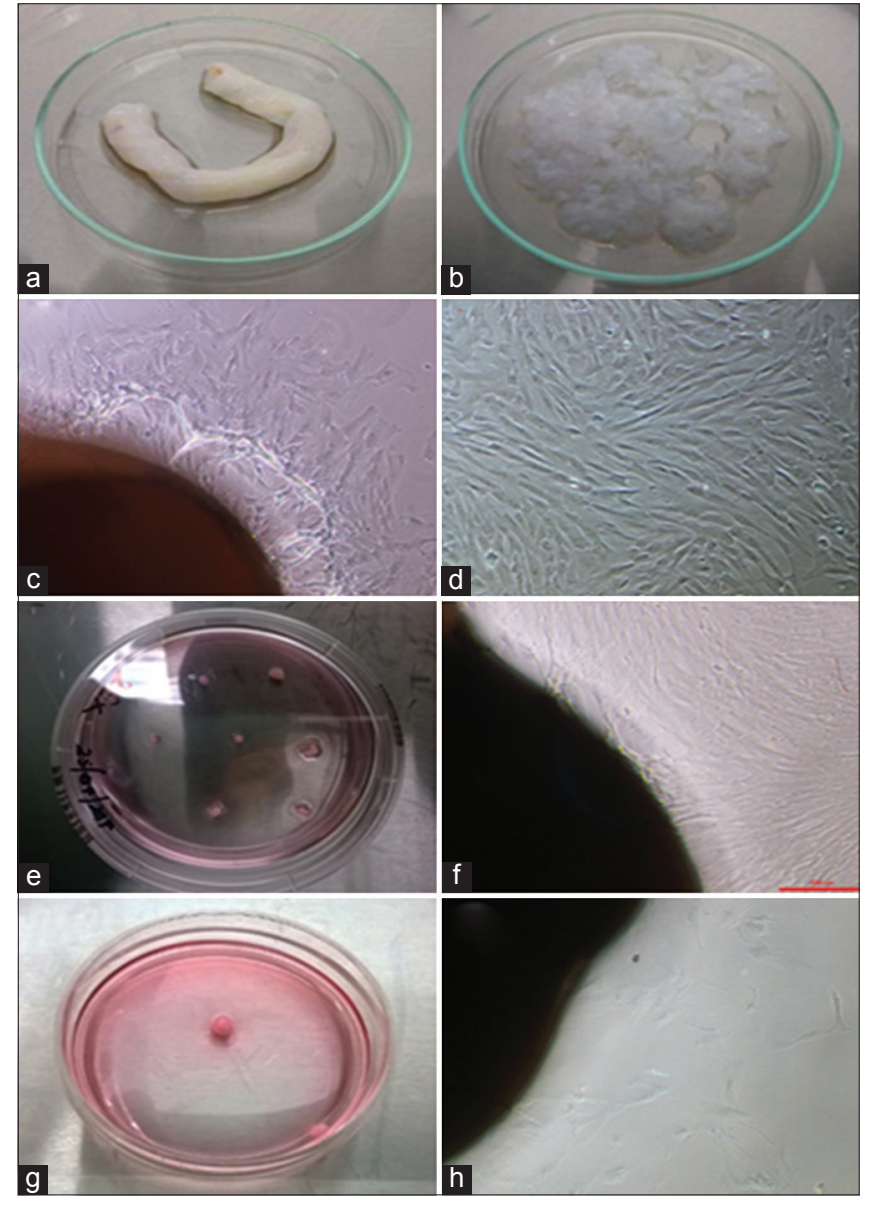

Figure 1: Isolation of hUCWJ by the ex-plant method. PBS washed umbilical cord (a) and chop umbilical cord Wharton's jelly. Cells migrated from explant day 7 (c). (d) Spindle/fibroblastoid structure of MSCs at P3 (10X). 2nd-time transfer explant (e) and migrated cells at day 2 (f). $5^{\text {th }}$ time transferred explant $(\mathrm{g})$ and migrated cells at day $2(\mathrm{~h})$

\section{differentiation.}

i) Adipogenic differentiation: The cell containing medium was aspirated from tubes containing cells with $50-60 \%$ confluence at the $3^{\text {rd }}$ passage and rinsed with $2 \mathrm{ml}$ phosphate buffered saline (PBS). $2 \mathrm{ml}$ of adipogenic differentiation medium, (Gibco, USA) was added; then incubated at $37^{\circ} \mathrm{C}$ and $5 \% \mathrm{CO}_{2}$ for 4 days. The medium was replaced with pre-warm adipogenic differentiation medium every 3-4 days. After 14 days of cultivation, the adipogenic culture was stained with Oil Red O staining, (Sigma, USA) to confirm that the MSCs had differentiated to adipocytes.

ii) Chondrogenic differentiation: The medium was aspirated from tubes containing cells with $70-80 \%$ confluence from the $3^{\text {rd }}$ passage and rinsed twice with $2 \mathrm{ml}$ PBS and trypsinized. The cell suspension was transferred to a $15 \mathrm{ml}$ centrifuge tube and pelleted at $1500 \mathrm{rpm}$ for 10 minutes. The pellet was resuspended in $200 \mu \mathrm{l}$ of complete medium and micromass culture was generated by seeding $3 \mu l$ to $5 \mu$ ldroplets on the 
culture plate. After cultivating micromass cultures for 2 hours, $2 \mathrm{ml}$ of prewarmed chondrogenic differentiation medium (Gibco, USA) was added to the culture plate and incubated at $37^{\circ} \mathrm{C}$ and $5 \% \mathrm{CO}_{2}$. The culture was re-fed with chondrogenic medium every 2-3 days. After 14 days of cultivation, chondrogenic pellets were stained with Alcian Blue Stain (Sigma, USA).

iii) Osteogenic differentiation: The cell containing medium was aspirated from tubes containing cells with $50-60 \%$ confluence at the $3^{\text {rd }}$ passage and rinsed with $2 \mathrm{ml}$ PBS. Then, $2 \mathrm{ml}$ of osteogenic differentiation medium (Gibco, USA) was added and incubated at $37^{\circ} \mathrm{C}$ and $5 \% \mathrm{CO}_{2}$ for 4 days. The culture was re-fed every 3-4 days with prewarmed osteogenic differentiation medium and incubated. After 21 days of cultivation, the osteogenic culture was stained with Alizarin Red S, (Sigma, USA).

CFU: Culture 100 cells/T25 mm culture flask in complete medium were incubated for 14 days in a humidified chamber of $5 \% \mathrm{CO}_{2}$ at $37^{\circ} \mathrm{C}$. Culture was washed with PBS and stained with $0.5 \%$ crystal violet (Himedia, India) in methanol for 10 minutes at room temperature. The plates were washed with PBS twice and colonies counted thereafter. A cluster that had more than 50 cells was counted as a colony under a microscope.

RNA extraction and Quantitative RT-PCR: Using TRIzol reagent (Sigma, USA), the RNA was extracted from the MSCs as per the manufacturer's instructions. A total of $3 \mu \mathrm{g}$ of total RNA was reverse transcribed to cDNA using Superscript III First-Strand Synthesis System (Invitrogen, Lithuania). The PCR (Genei, India) was performed by using the PCR master mix (Puregene, USA) with the sets of primers (Table 1). PCR conditions included an initial denaturation of 5 minutes at $94^{\circ} \mathrm{C}$, followed by 35 cycles of 30 seconds denaturation at $94^{\circ} \mathrm{C}, 45$ seconds at annealing temperature and 30 seconds extension at $72^{\circ} \mathrm{C}$, with a final elongation step at $72^{\circ} \mathrm{C}$ for 7 minutes. Amplified products were separated by electrophoresis (Genei, India) on a $2 \%$ agarose gel, (Promega, USA) and observed by ethidium bromide (Promega, USA) staining under Gel Doc - IT 310 imaging system (UVP, USA).

\section{RESULTS}

Human neonate derived Mesenchymal stem cells were isolated from UCWJ by this modified explant method and the cultures were studied in early passages. Wharton's Jelly MSCs isolated by enzymatic digestion and explant culture possess the same characteristics. However, the modified explant method has several advantages over enzymatic isolation.

Explant isolation of MSCs and morphology analysis It has been observed that in an average of 7 days, the MSCs start migrating from UCWJ explant (Figure 1c). In optimal culture condition, it is adherent to plastic as monolayer cells and the migrated cells have a heterogeneous cells population with prominent nuclei. By $3^{\text {rd }}$ passage, it becomes more uniformly spindle shape with a homogeneous population of MSCs (Figure 1d).

The explant was reincubated for a total of 5 times. The first and the second reincubation of explant culture start to migrate cells within 24 hours and adhered to plastic as monolayer cells with heterogeneous cells population (Figure 1e and 1f). But by fifth reincubation of explant, the migration rate was seen to slow down (Figure $1 \mathrm{~g}$ and $1 \mathrm{~h}$ ).

\section{Characterization of MSCs by Immunophenotypic}

Explant derived MSCs at $3^{\text {rd }}$ passage were analyzed by flow cytometry. It expressed positive markers CD73, CD105, CD90 and CD44 but lacked expression of MSC cocktail (PE CD45, PE CD34, PE CD11b, PE CD19 and PE HLA-DR) for all the cells population (Figure 2) as defined by the ISCT criteria.

\section{Trilineage differentiation of MSCs}

Adipogenic differentiation characterised by the appearance of lipid vacuoles was seen as early as 7 days in adipogenic differentiation medium (Figure 3a). After 14 days, the cells were fixed with $4 \%$ formaldehyde and adipogenesis was confirmed by Oil Red $\mathrm{O}$ staining of the vacuoles (Figure 3d).

Under chondrogenic differentiating medium, the cells start aggregating within 2-3 days. After 14 days of culture

\section{Table 1: Primer sequence for PCR reactions}

\begin{tabular}{llcc}
\hline Name & Sequence & Product size & Genebank reference no. \\
\hline CD 90 & F - CTAGTGGACCAGAGCCTTCG & $236 \mathrm{bp}$ & NM_006288.2 \\
& R - TGGAGTGCACACGTGTAGGT & & NM_000118.1 \\
CD105 & F- TGCCACTGGACACAGGATAA & $204 \mathrm{bp}$ & NM_001101.2 \\
& R- - FCTTCGAGACCTGGCTAGTG & $207 \mathrm{bp}$ & \\
& F- TCCTTCCTGGGCATGGAG & & \\
\hline
\end{tabular}


(Figure 3b), a spheroid cell mass was formed which was fixed with $4 \%$ formaldehyde solution and stained with Alcian Blue (Figure 3e). The blue staining indicated the synthesis of proteoglycans by chondrocytes.

Osteogenic differentiation was seen from day 10 in osteogenic differentiation medium and the MSCs started showing mineralization (Figure 3c). The MSCs were further cultured for 21 days and fixed with 4\% formaldehyde. Calcium depositions, a sign of osteogenic differentiation were checked and confirmed using Alizarin Red S (Figure 3f).

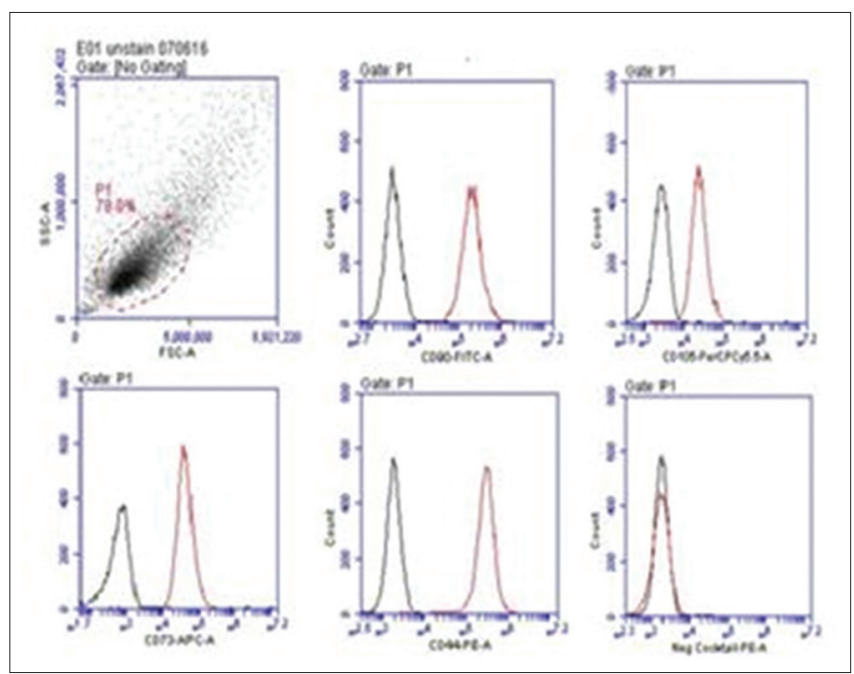

Figure 2: Expression of the cell surface markers (CD90, CD105, CD73, CD44) and lack expression of negative cocktails (PE CD45, PE CD34, PE CD11b, PE CD19 and PE HLA-DR) (red lines) when compared with the positive and negative iso-type control cocktails (black lines). The plots were derived from gated events based on light scattering characteristics of the MSCs at passage 3. Cells were analyzed using BD Accuri C6 flow cytometer

\section{CFU}

The efficiency with which they form colonies still remains an important assay for the quality of cell preparations. Assays for colony forming units offer a convenient means of assessing the proliferative capacity that MSCs retain after the cells have been expanded in culture. CFU assays were well characterized and validated in the in vitro assays (Figure 4).

\section{RT-PCR}

MSCs isolated from hUCWJ were used to perform RT-PCR and show strong expression of MSCs associated markers CD90 (thy-1) and CD105 (endoglin). It also expressed housekeeping gene $\beta$-actin using specific primers (Figure 5).

\section{DISCUSSION}

MSCs from birth associated tissues are readily available, with minimal access and intervention considered primitive when compared to adult tissues like adipose tissue. The most common method for isolating MSCs from hUCWJ is enzymatic digestion and explant technique. ${ }^{21}$ When compared to enzymatic digestion, the explant yield less heterogeneous cells with higher proliferation rate, though the explanted tissue takes more time to migrate the cells. ${ }^{22}$

Successful isolation of MSCs from Wharton's jelly depends on the collection, processing and prevention from floating of explant tissue. For the cells to migrate, it is very important for the explant tissue to adhere to the culture plate. One common method used is to place a sterile coverslip on top of the explant giving it some weight to allow the explant to adhere to the culture vessel. But this process has the disadvantage of slipping the coverslip from

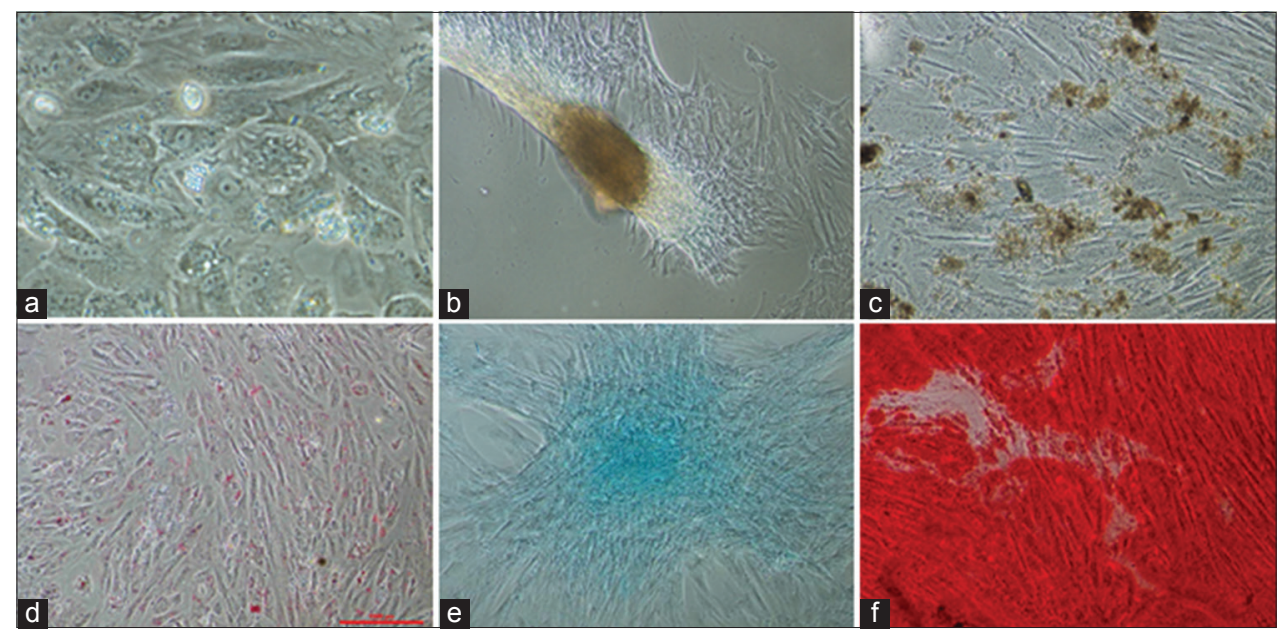

Figure 3: Trilineage differentiation of hUCWJ: Adipogenic differentiation (3a) unstained lipid droplets (3d) lipids droplet stain confirmed with Oil Red $\mathrm{O}$ for adipogenic differentiation. Chondrogenic differentiation. (3b) unstained chondrocytes. (3e) Glycosaminoglycans in cartilages for chondrogenic differentiation confirmed with Alcian Blue staining. Osteogenic differentiation. (3c) unstained osteogenic differentiation (3f) Calcium salts binding in osteogenic differentiation confirmed with Alizarin Red S 

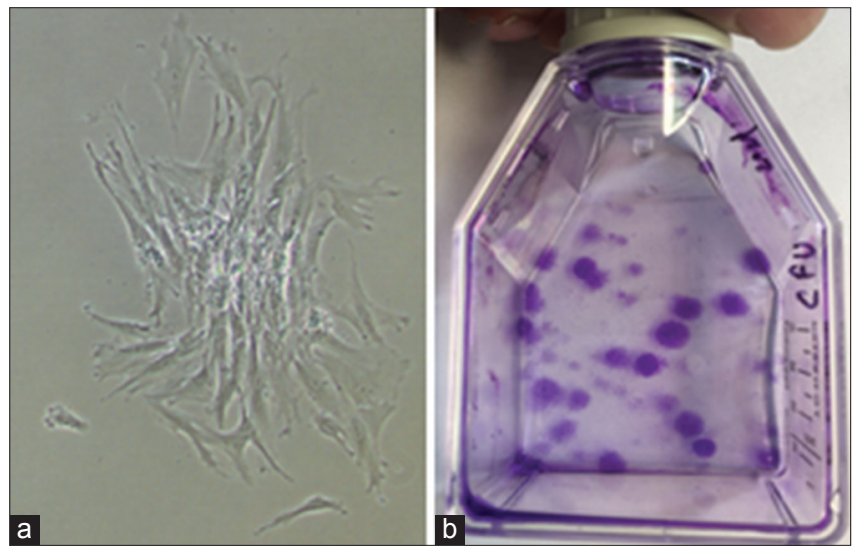

Figure 4: Single Colony before staining (a). Colonies after staining with crystal violet (b)

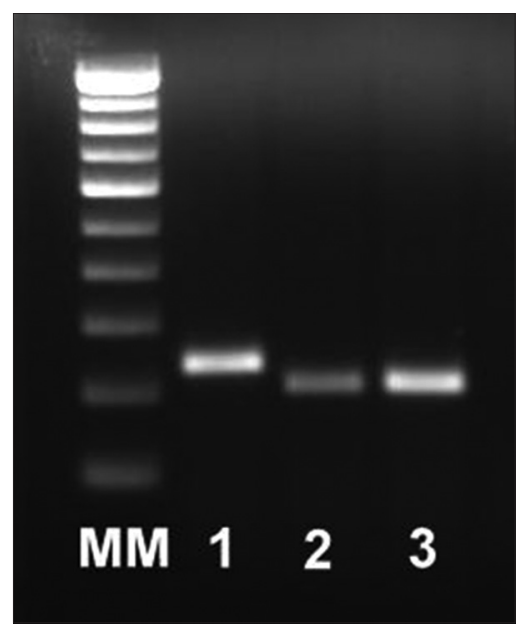

Figure 5: Analysis of MSCs associated markers thy-1(lane-1), endoglin (lane-2) and housekeeping gene $\beta$-actin (lane-3) is shown using specific primers in human umbilical cord Wharton's jelly by reverse transcriptase polymerase chain reaction (RT-PCR)

explant while adding the media and during movement of the culture plates. Mori et al used stainless steel mesh and reported that he can observe the early migration of the cells and yield high when compared to conventional explant technique. ${ }^{23}$ In our study under the biosafety cabinet, we allow the explant to stand on the culture plate for 10, 20 and 30 minutes before transferring the medium. This exposure time allows the explant to adhere properly to the culture plate for proper migration of the cells but the exposure duration of 10, 20 and 30 minutes gives a similar result as the cells migrated in an average of 7 days with equal numbers of cells at $\mathrm{PO}$.

In comparison to adult tissue derived MSCs, the neonatal MSCs demonstrated 2 fold higher colony forming efficiency. All the culture cells from Wharton's jelly show typical fibroblastoid morphology and differentiated into adipogenic, chondrogenic and osteogenic lineage as per criteria. ${ }^{20}$ The immunephenotyping of explant derived
Wharton's jelly MSCs expressed more than $99 \%$ of CD 90 , CD73 and CD44 and expression of CD105 were above $92 \%$ of the cells populations. The negative markers were expressed by less than $2 \%$ of the total cell populations but Trivanović $\mathrm{D}$ et al in their study of UCMSCs showed lower expression of MSCs markers, as they were negative for CD90 and slightly positive for CD105 (6-10\%) and CD44 (10-30 \%)..$^{18}$

A similar result was observed in our study as a gradual change in size was observed during the later passage with no change in the morphology of MSCs up to 3-4 passage. ${ }^{24,25}$ Again, the MSCs expand until 19 passage without any growth factors like bFGF-2, unlike Zuraidah et al used bFGF-2 to generate and expand until passage 20.24

Out of the 22 samples, all the explant migrated cells (i.e. $100 \%$ ) but 16 (i.e. $73 \%$ ) sample fulfil the defining criteria. ${ }^{20}$ Proper isolation and a good number of cells are required for research as well as for therapeutic applications. Therefore, in our study to increase the number of primary cells in large scale instead of discarding the explant, we transferred the Wharton's jelly explant after a successful migration from the primary culture vessel to another for 5 subsequent times to maximize on the number of primary cell migration from the primary explant.

There are three main benefits of transferring the explant instead of discarding it. First, it's a assure success for the isolation of MSCs as it has already been migrating cells before. Second, after transferring the explant, the cells started migrating within 24 hours when compared to primary explant which took around 7 days in an average. Third, there is no requirement of collecting fresh umbilical cord sample which in turn save processing time, the cost for the transport medium and reduce contamination chances while transporting and processing the umbilical cord sample.

\section{CONCLUSION}

MSCs isolated from adult tissue has a significant clinical application but due to the age related decrease in the growth, differentiation capacity and limited cell numbers lead to the search for alternatives. Explant derived hUCWJ MSCs culture has an advantage of non-invasive, collection procedure with limited ethical concern and are time and cost efficient. The numbers of explant leading to cell migration are not uniform even if it is from the same tissue; therefore starting with multiple explants allowed selection of explant with the best migration of cells to optimize the yield of cells by subsequent transfers of the selected explant. The explant showed potential for its cells 
to migrate after it was transferred from one culture plate to another for 5 consecutive times. This study characterised the MSCs and proved that the modified explant was time and cost efficient in MSCs yield, but could not quantify the yield of cells for therapeutic application hence it may be explored in future studies.

\section{ACKNOWLEDGEMENTS}

We would like to sincerely thank the Indian Council of Medical Research (ICMR) for funding our research project (ICMR No: 5/7/1268/2015-RCH). And we would also like to thank IL Biotech Hub Project (Sanction No. 102/ IFD/SAN/5881/2010-11), NER-BPMC, Department of Biotechnology (DBT) India, for its support. Finally, we would like to thank Dr. Amlan Gupta, Professor, Department of Pathology, Sikkim Manipal Institute of Medical Sciences for his help.

\section{REFERENCES}

1. Friedenstein AJ, Deriglasova UF, Kulagina NN, Panasuk AF, Rudakowa SF, Luriá EA, et al. Precursors for fibroblasts in different populations of hematopoietic cells as detected by the in vitro colony assay method. Exp Hematol 1974; 2(2):83-92.

2. Bunnell BA, Flaat M, Gagliardi C, Patel B and Ripoll C. Adiposederived stem cells: isolation, expansion and differentiation. Methods San Diego Calif 2008; 45(2):115-120.

3. Ohyama M, Zheng Y, Paus R and Stenn KS. The mesenchymal component of hair follicle neogenesis: background, methods and molecular characterization. Exp Dermatol 2010; 19(2):89-99.

4. Veréb Z, Póliska S, Albert R, Olstad OK, Boratkó A, Csortos C, et al. Role of Human Corneal Stroma-Derived MesenchymalLike Stem Cells in Corneal Immunity and Wound Healing. Sci Rep 2016 19; 6: 26227.

5. Perry BC, Zhou D, Wu X, Yang F-C, Byers MA, Chu T-MG, et al. Collection, cryopreservation, and characterization of human dental pulp-derived mesenchymal stem cells for banking and clinical use. Tissue Eng Part C Methods 2008; 14(2):149-156.

6. Marędziak M, Marycz K, Tomaszewski KA, Kornicka K and Henry BM. The Influence of Aging on the Regenerative Potential of Human Adipose Derived Mesenchymal Stem Cells. Stem Cells Int2016; 2016:2152435.

7. Kadam SS, Tiwari S and Bhonde RR. Simultaneous isolation of vascular endothelial cells and mesenchymal stem cells from the human umbilical cord. In Vitro Cell Dev Biol Anim 2009; 45(1-2):23-27.

8. Kadam S, Govindasamy V and Bhonde R. Generation of functional islets from human umbilical cord and placenta derived mesenchymal stem cells. Methods Mol Biol Clifton NJ 2012; 879:291-313.

9. Wang H-S, Hung S-C, Peng S-T, Huang C-C, Wei H-M, Guo Y-J, et al. Mesenchymal stem cells in the Wharton's jelly of the human umbilical cord. Stem Cells Dayt Ohio 2004; 22(7):1330-1337.
10. Troyer DL and Weiss ML. Wharton's jelly-derived cells are a primitive stromal cell population. Stem Cells Dayt Ohio 2008; 26(3):591-599.

11. Pappa KI and Anagnou NP. Novel sources of fetal stem cells: where do they fit on the developmental continuum? Regen Med 2009; 4(3):423-433.

12. Marcus AJ and Woodbury D. Fetal stem cells from extraembryonic tissues: do not discard. J Cell Mol Med 2008; 12(3):730-742.

13. Weiss ML, Anderson C, Medicetty S, Seshareddy KB, Weiss RJ, Vander Werff I, et al. Immune properties of human umbilical cord Wharton's jelly-derived cells. Stem Cells Dayt Ohio 2008; 26(11):2865-2874.

14. Chamberlain G, Fox J, Ashton B and Middleton J. Concise review: mesenchymal stem cells: their phenotype, differentiation capacity, immunological features, and potential for homing. Stem Cells Dayt Ohio 2007; 25(11):2739-2749.

15. Kim D-W, Staples M, Shinozuka K, Pantcheva P, Kang S-D and Borlongan CV. Wharton's jelly-derived mesenchymal stem cells: phenotypic characterization and optimizing their therapeutic potential for clinical applications. Int J Mol Sci 2013;14(6):1169211712.

16. Hendijani F. Explant culture: An advantageous method for isolation of mesenchymal stem cells from human tissues. Cell Prolif 2017; 50(2).

17. Yoon JH, Roh EY, Shin S, Jung NH, Song EY, Chang JY, et al. Comparison of explant-derived and enzymatic digestion-derived MSCs and the growth factors from Wharton's jelly. Bio Med Res Int 2013; 2013:428726.

18. Trivanović D, Kocić J, Mojsilović S, Krstić A, llić V, Djordjević IO, et al. Mesenchymal stem cells isolated from peripheral blood and umbilical cord Wharton's jelly. Srp Arh Celok Lek 2013; 141(3-4):178-186.

19. Tong CK, Vellasamy S, Tan BC, Abdullah M, Vidyadaran S, Seow HF, et al. Generation of mesenchymal stem cell from human umbilical cord tissue using a combination enzymatic and mechanical disassociation method. Cell Biol Int 2011;35(3):221-226.

20. Dominici M, Le Blanc K, Mueller I, Slaper-Cortenbach I, Marini F, Krause D, et al. Minimal criteria for defining multipotent mesenchymal stromal cells. The International Society for Cellular Therapy position statement. Cytotherapy 2006; 8(4):315-317.

21. Seshareddy K, Troyer D and Weiss ML. Method to isolate mesenchymal-like cells from Wharton's Jelly of umbilical cord. Methods Cell Biol 2008; 86:101-119.

22. Salehinejad $P$, Alitheen NB, Ali AM, Omar AR, Mohit M, Janzamin $E$, et al. Comparison of different methods for the isolation of mesenchymal stem cells from human umbilical cord Wharton's jelly. In Vitro Cell Dev Biol Anim 2012; 48(2):75-83.

23. Mori Y, Ohshimo J, Shimazu T, He H, Takahashi A, Yamamoto Y, et al. Improved explant method to isolate umbilical cordderived mesenchymal stem cells and their immunosuppressive properties. Tissue Eng Part C Methods 2015; 21(4):367-372.

24. Yusoff Z, Maqbool M, George E, Hassan R and Ramasamy R. Generation and characterisation of human umbilical cord derived mesenchymal stem cells by explant method. Med J Malaysia 2016; 71(3):105-110.

25. Stolzing A, Coleman N and Scutt A. Glucose-induced replicative senescence in mesenchymal stem cells. Rejuvenation Res 2006; 9(1):31-35. 
Authors Contribution:

TPS- Literature search, Review of literature, Manuscript preparation, Concept and Design of the study, prepared first draft of manuscript and critical review of study proposal; MLS- Scientific advisor critical review of study proposal and helped in preparing first draft of manuscript; AP- Concept of study, Data collection and scientific advisor critical review of study proposal; TAS- Scientific advisor critical review of study proposal and helped in preparing first draft of manuscript.

Work attributed to:

Sikkim Manipal Institute of Medical Sciences, Sikkim Manipal University, Gangtok, Sikkim, India.

Orcid ID:

Dr. Takhelmayum Paras Singh - (iD https://orcid.org/0000-0001-9222-3305

Prof. Mingma Lhamu Sherpa - (D) https://orcid.org/0000-0002-5905-6127

Prof. Anup Pradhan - (1) https://orcid.org/0000-0001-8149-4759

Prof. Takhelmayum Amumacha Singh - (1) https://orcid.org/0000-0003-0023-0482

Source of Support: Indian Council of Medical Research (ICMR) for funding our research project (ICMR No: 5/7/1268/2015-RCH). And IL Biotech Hub Project (Sanction No. 102/IFD/SAN/5881/2010-11), NER-BPMC, Department of Biotechnology (DBT) India, for its support, Conflict of Interest: None declared. 